\title{
Erratum to: Acotiamide: First Global Approval
}

\author{
Mary L. Nowlan · Lesley J. Scott
}

Published online: 4 June 2014

(C) Springer International Publishing Switzerland 2014

Erratum to: Drugs (2013) 73:1377-1383

DOI 10.1007/s40265-013-0100-9

The first author's name, which currently reads:

Mary L. Nolan

Should read:

Mary L. Nowlan

The online version of the original article can be found under doi:10.1007/s40265-013-0100-9.

M. L. Nowlan $(\square)$

Adis R\&D Insight, 41 Centorian Drive, Private Bag 65901, Mairangi Bay, North Shore, 0754 Auckland, New Zealand e-mail: dru@adis.com

\section{J. Scott}

Adis, Auckland, New Zealand 